\title{
8. INDUSTRIAL DESIGN: THE ROLES AND FACTORS OF AESTHETICS, MODELING, STYLING, PRODUCT BRAND AND BRANDING IN DESIGN/DESIGN EDUCATION
}

\author{
Obasuyi Osa-Francis Efer ${ }^{79}$
}

\begin{abstract}
This paper examined the roles and factors of Aesthetics viz-a-viz those of modeling, styling and the product Brand (Branding) as viewed against their fundamental relevance as core ingredients for the actualization of any Design initiative and creative endeavour. These roles, influences and place of Aesthetics (and its allied components, makes up the very soul, content and essence of what the product is all about. Its Form, Shape, Morphological / physical attributes and characteristics. The paper established that the aesthetic components of beauty, colour, shape, (form) fonts, (lettering or typography) and all other general Aesthetic Ambience gives the given product the desired quality/beauty that it exudes to help determine its marketability / profitability as a Brand. The paper also reviewed the aspects /implications of these roles and influences on Design Education alongside highlighting the potentials of the Design Educator - learner experience, while exploiting the Teachers ability to effectively harmonise the various approaches and practices of a functional Design-led Educational programme viz-a-viz piloting such talents/skills achieved to practicable and useful ends as professionals in Design and Technology. The paper also seeks to establish that the roles and factors of modeling styling and Branding of the product which is best exemplified through the adaptation of Design inputs and features such as ornamentation, edge delineation, texture movement/flow of linear form, symmetry or Assymetry of shapes, colour, granularity (of matter/particles large or small) or coarseness, play of light (sunlight) and shade, transcendence (state of being or existence of a product beyond the limits of material experience) and that of total harmony. The paper recommends that for any product Brand to succeed it must incorporate all of the above components together with the inclusion of the other qualities that makes up the intangible content of the Brand such as, Brand Name, Logo, Tagline (catchphrase) the Graphics (elements of Design) Brand Shape, Brand colour, culminating in the establishment of what the Brand mission statement is about, its function, role or job it is intended to perform.
\end{abstract}

Key words: Granularity/Coarseness,Transcendence of material, Alliteration, Initialism, Neologisms of Brand, "Form Begat Form”, Form Follows Function

\section{Introduction}

The industrial design enterprise and profession has come a long way since the second half of the $19^{\text {th }}$ century. The pioneers of the profession never envisaged that the discipline will single handedly help change the face of our world, the nature, context and characterization of the material culture and consequently the man-made environment, for good. According to Lucie-Smith (2001) who says that "the phenomenology of change of civilization from its early subsistence agrarian economy to a new world order was brought about by the advent of New Technologies / Inventions for industrialization in the Age of the industrial Revolution. That was brought about by an adaptation to the serial nature of the factory Assembly lines and means of production of goods, mass

\footnotetext{
${ }^{79}$ Senior Lecturer PhD., University of Benin, from Benin City, Nigeria, email: yandref201384@ gmail.com
} 
produced solely for commercial purposes. This new reality of mass production techniques totally helped to eradicate the time honoured Traditional, of the unitary systems of custom-made (customized, hand-crafted),/Artisan methods of production of local goods which were made to order, either for patrons or wealthy upper class clients in society. This Aspect of production of handcrafted masterpieces by master craftsmen, seemed to have been lost forever to the Age and Advent of the Machine (Assembly line) and New means of Mass production/manufacture.

Loewy (1980) in his submission, observed that, "the New Factors of production together with the New expertise and competencies in modern techniques and Technology that emerged therefrom" was responsible for the changes so stated above. Thereby giving rise to new entrepreneural breakthroughs in skills and service delivery. The Dawn of Advertising and New means of communication suddenly changed the whole dynamics of the economic growth of the developed Nations of the world. This being the case, the numerous goods and services made available by these factories, needed to be sold and distributed. Competition became stiff amongst manufacturers. The demand for consumer goods in the late 1800's and early 1920's were at its peak. This demand was also dictated by new consumer benchmarks of not just only functional goods but that they should also be Aesthetically appealing, to warrant purchase. So saw the concept of quality, Beauty and Aesthetics (of the Product Brand / Branding) suddenly became the yardstick that dramatically changed the whole scenario and Dynamics of the methods of production. With the resultative increase in volume of goods produced, so also saw an increase in demand for consumer goods and an increase in consumer preferences for quality, aesthetics and performance (function) of such goods. This became the primary concern of most of the products manufacturers. So strong was the debate, urgency and need for experts whose job it was to change and provide these missing components of Aesthetics, Beauty and Style in the new products. This search for quality, beauty and Aesthetics also brought about the dawn of the Age of the Industrial Designers (who could also be called Aestheticians in their own right).

\section{New Roles and Dialogue of the factors of Quality and Aestethetics in Product Branding}

Along that same Dialogue, the concept of quality before now tends to allude to and align with the principles and belief of the 3Fs, that "FORM" "FOLLOWS" "FUNCTION" or that "FORM BEGAT FORM". In the era of the Industrial Revolution it was believed that if a product was functional therefore it must be a good product. This template later proved to be so faulty, that if a product functions doesn't necessarily mean it must be good. According to Papanek (2009) who believes that consumers are first and foremost, human beings, with a body, soul and spirit and therefore would always be drawn to or attracted by products/services that bears or carries the attributes that is in tune with their cultural, socio-economic preferences. Even sometimes seeking products that qualifies or satisfies their Ego or Status symbol in society. 
So the need for a new way of production definitely became the only alternative. The Advent of industrial design and roles of the industrial Designers, Architects, product Stylists and Design Aestheticians, became ever more urgent and pertinent. The inclusion of these groups of professionals in the production process saw a marked deviation from the old and tedious methods of production of goods. The out come of the infusion of this component resulted in products, such as the Refrigerator, the Telephone, Television, automobiles and even the Aeroplane. The standard of living and life of the middle class in society changed forever. The Age of commercialization, Tele-communication, Advertising and the subsequent Advent of computer Technology all helped brought about the change that mankind had never thought possible. (Wilson, 2002). With the Advances in computer (IT) Technology, computer aided design, modeling and styling became the trend rather than the norm. The era of digital imaging 3D digitally generated prototypes and models took center stage. Although the place and need for the physically produced hand made or sculpted prototypes and models, (An aspect of modeling which has to do with the FORM or SHAPE of the product,) has since been replaced by functions and roles performed by ROBOTS and ROBOTICS Engineering.

Advances in computer modeling and cybernetics is become the Trend. Although it cannot replace the need for the execution of physical prototypes/modeling (models made by hand). Modeling has to do with the SHAPE, FORM or MORPHOLOGY of the object- which demands enlisting the studio practice skills of modeling and styling, that will help improve the Physical state or Aerodynamics and Aesthetic outlook of the given product. (Shimura et. al., 2012).

\section{The Role of Aesthetics in Product Branding and Design}

The Role influence and place of the aesthetic component in a products life, according to Korsmeyer (1998) could be said to be what makes-up the very spirit, soul, content, and essence of what the product is all about. Its Form, Shape, Morphological and Physical attributes, characteristics and all other such properties that often times determines whether the product brand will be successful in the market place or not. By the aesthetic component of the product we mean the beauty, colour, shape (form), fonts, (lettering or typography) and the general aesthetic Ambience that the given product exudes or carries which often determines its marketability, profitability and success as a Brand. The Anthological history of Aesthetics (on the other hand) dates back to Ancient Greece from where the Greek words - "aisthetikos" meaning "esthetic" pertaining to sense perception. Which in turn was derived from the Greek word "aisthanomai" meaning to perceive, feel, or sense.

According to Korsmeyer (1998) in her work on "Aesthetics", she acceded to the meaning of Aesthetics to being related to the studies and philosophy of Art. She continued by saying that it is concerned with the study of beauty and taste, often times known for its relationship with the interpretation of works of Art, Art movements and the theories of Art, Aesthetics, and Design principles. The term Aesthetics in Design could be used to describe particular styles and 
principles in creativity which might include ornamentation, edge delineation, texture, movement/flow of linear form, symmetry, colour, granularity (which means the quality of being composed of large or small particles) or coarseness, the play of light (sunlight) and shade, transcendence (which means a state of being or existence above and beyond the limits of material experience) and culminating in that of the total harmony of the Design in question. So a correlation of all these put together with that of the fundamental role of Aesthetics in Design (and product Branding) could very much resemble a Design scenario where "the Designer skillfully and carefully arranges the visual and physical elements of Design (in a given product) such as those stated above colour, material, form, Brand / Branding characteristics, even the degree and play of light (or lighting materials) to generate maximum visual impact in the products uniqueness and to give it that extra edge over its competitors".

The role of Aesthetics in the Design could also include such skillful manipulations of the products material and physical content to achieve an Ephemeral quality. i.e. The use of materials like Transparent plastics or glass for example allows the background around the product to blend through the given product. The use of fine wire mesh membranes for example, that flows and blends with the lightness of solidified smoke, the use of gauzy transluscent fabrics that floats and diffuses with light, use of reflective panels that blends into the surrounding skies. All these techniques and materials used in the creative process helps create an almost "ghost - like" feeling about such a given product or Brand. Such is the allure, power and role of the Aesthetical component in design. According to Wilson (2002) who postulates that the "Aesthetic and visual symbols of a product can be deeply cultural, added to that he says, that the set of the given functions of that product can vary from one culture to another".

\section{The Role of the Brans/Branding in Design}

Put succinctly, the Role of the Brand (or Branding) of a product is intrinsically related to the value, service and function the product is intended to perform in the life (lifestyle) of the intended consumers. The meaning and definition of a brand or product brand according to Frankenberger et al. (1998) could be said to be "a recognizable kind of thing or object". Continuing it could also be said to represent "a name given to an object, product or service, that marks it or labels it by a distinctive word, sign or symbol, which indicates exclusive right of usage". Like the branded merchandise that bears or wears a standard brand Image, Name or Logo. Putting the above presupposition in a much more specific context, the product or (Brand) in this scenario according to Frankenberger et.al (1998) Ibid. could be defined or described as, "a group or a set of objects that serves specific utilitarian purpose or function. They always must possess particulate / specific Aesthetic qualities that must embody certain symbolic representation and significance". Along those premises therefore Branding could be deduced to mean "the act of marking or labeling an object or product with a Trade name or Brandmark that is protected by a patent". Which means the product can only be produced and sold exclusively by the said 
company holding the patent rights. As for (Brand/branding), the original roots and meaning could be traced wayback to the wild west of the United States of America, where cattle owners / ranchers had to brand their cattle as merchandise for purchase and ownership with the help of a Branding metal, which is put into Red hot coal fire and used to Burn into the Raw skin of the cattle / livestock to indicate ownership.

According to Ollins (2003) The Anthology of the word Brand came from the old Nordic (Germanic) word "Brands" which means "to burn' which could be traced even to early Agrarian civilizations and Animal Husbandry. (500 BC $1100 \mathrm{BC}$ ). So the issue of Brand/Branding of a product resulted from the need by manufacturers (during the industrial Revolution) to help sell their (massproduced) goods to a wider mass market. The earliest known brands that quickly adopted this Trend were Pears soap, Campbell's soap, Coca-cola soft drink, Quakeroats etc. They were amongst the first products in America to be branded. Soon Kellogg's Cornflakes and Uncle Ben's Rice followed suite. (Knapp, 2008). Further developments of this practice soon saw manufacturers quickly adopting various strategies of how to build their brand's identity and Brand personality. With a little bit of the addition of such qualities such as humour, fun, a component of luxury, taste and demographics (youth appeal) contents. This forms the foundation of how the practice of product Brand and Branding actually evolved and is still in practice to date.

In their individual and separate summations, Schmidt et al (2002) opined that a Brand/ Branding could also be referred to as, " a set of marketing and communication strategies or methods which helps to distinguish one individual, or groups of people or a company from their competitors". Pushing that further it is believed that the key components that makes up a Brand consists of the Brands identity like its logo and Trademark. Consequently a brand could be said to mean a name, term, design symbol or other features that distinguishes one product from those of its competitor. Their applications are seen in Business marketing, and advertising of which livestock Branding as stated earlier is the oldest form of branding in contemporary circumstances.

\section{Qualities of a Product Brand}

According to Martins (2000) who stated that the qualities or components of a product Brand (or Brands) typically comprises (or is made up) of the following elements / characteristics:-

i. Brand Name: Which is (or are) the word/words used to identify the Brand, product, service, concept or company.

ii. Brand Logo: The visual elements, symbols or trademark that helps identifies the Brand.

iii. Tagline or Catchphrase: "Coke is it" was the catch phrase for the Coca-cola Brand in 1980's.

iv. Graphics/Graphic Design: The visual graphic elements that makes up the Brand's visual identity.

v. Brand shape/s: The distinctive look, shape and form of the Brand, e.g VW. Beetle, and the Coca-cola bottle shape. 
vi. Brand colour/s: Selection of that unique colour/s that distinguishes the Brand from its competitors e.g Google Colours.

Also there exists certain attributes that can be associated with product Brands. For example the term Brand Name can be used interchangeably with the Brand or its trademark. The various types, styles and characteristic examples of Brand Names according to Knapp, D. (2008) Ibid. includes some of the following:

- Initialism:- Used to denote a Brand name made up of only the initials e.g IBM, DHL etc.

- Descriptive Brand Name:- It describes a product's benefits or function.

- Alliteration and Rhyme:- Brand Names that Rhyme and are fun to say/pronounce.

- Evocative:- Brand Names that evoke vivid images of emotions or appeals to the Ego of the consumers.

- Neologisms:- These are Brand Names that are completely made-up or created from nothing.

- Founders Names:- Real peoples Names or founders of the company e.g. Disney etc.

- Personification:- Adopting Names of mythical figures or Names of Heroes e.g. Quaker oats, W.K Kellogg Cornflakes.

- Combination:- A combination of multiple words put together to create one word e.g. Microsoft, (micro, computer, software) Vodafone ('Voice' 'data' 'telephone').

\section{Strategies for Creating a Product Brand}

Ollins, W (2003) ibid, in his work "on Brand" describes or outlines 7 (seven) unique strategies for creating a product Brand and they include the following:

(a) The first strategy to adopt, is to acknowledge that "Your Brand is You", it must be a direct reflection of your personality. "So KNOW WHO YOU ARE" or "KNOW WHAT YOUR PRODUCT BRAND IS ALL ABOUT." And write down what the Brand mission statement is all about. What is its purpose, and what is the product meant to do or what is the products function, role or job. How is the product different from the others/ competitors. What does the product intend to accomplish.?

(b) Generate an individual or personal outline of the products characteristics, qualities and make up. Provide every detail of the products content, function and make - up as conscise as you can. Create a great 2D visual Design initiative that best represents what the product, looks like in full-colour, size and rendition.

(c) Be deliberate to pick out 3 (Three) unique words that best describes the product as a brand. Words that can drum up consumer patronage and desire to buy.

(d) Generate an image portfolio for the brand, this includes, images, typography / fonts graphics, colours that appeals (suits) the product's image, and all other design components that best elucidates the products best qualities (points). 
(e) Finalize the choice of your product's brand colours, the lettering / typography that goes on it and all other brand elements that will complement the overall look or Aesthetics of the finished product.

(f) Create and generate a logo (Logotype) for the product Brand. The logo design must be iconic enough for it to stand the test of market trends / times. It must contain such qualities that definitely will appeal to the target Audience.

(g) Create a product Brand style. This is the ultimate lists of contents of the products specific colours, fonts (lettering or typography,) images or various elements of Design, used to exemplify the product and its 3 keywords and mission statement. This is to aid and ensure high standards and consistency in the products life span. This is to ensure that your product sticks to the brand standards it had set from the "get go" and get it ready for the market your product and Brand is complete and ready to conquer/take over the market of its competition.

\section{Approaches in Design - Led Educational Practice: A Synthesis of its Implications and Importance in Design Education}

Quoting Billington and Baynes (1978) observed in his study and said that, "the teaching of Design in schools could best be achieved through an integrated approach rather than as a separate programme for Art, craft and Technology courses". Furthermore he opined that a basic course could be developed which aims at giving a strong impulse to creative designs through a disciplined and well ordered series of experiences, but which is at the same time "geared" towards the skills and experience of the students. In the same context, Rusu et.al. (2015) stressed the need for the Arts/ Design Education to be given its priority / pride of place, as being one of the most important educational elements and purpose in a child's education. This they (collectively) say is an attempt aimed at developing the total personality of the child, thereby helping to model his/her character and behaviour in society. Continuing the teacher they say is the central figure (in this process) who uses such good communicative skills to affect and stimulate the creativity impetus/interest of the child, thereby helping to provide and establish that "positive evolution of self - expression, self knowledge (self worth) that enhances better interpersonal relationships both in academic education and society at large". In the first undergraduate years, it is believed,(they continued) "that the approach to all design problems needs to be streamlined with a bias towards design intuitiveness, ingenious technical/technological responses and result oriented reasoning". From the above it was deduced that a fresh Design education approach is needed that will: i. Lead towards a conscious and critical awareness of ethical, emotional and aesthetic values, technical possibilities, resulting in the ability to make valid intellectual Design decisions (Design Awareness)

ii. Extend and improve the graduates/learner's skills and faculty to bring conceptual Design ideas to physical fruition (Design Activity) 
iii. Make conscious, the experience and satisfaction of this creative activity, that will engender creative abilities which will result in tangible products (Design Manufacture)

The teaching of Design (including Engineering Design) in schools must be made to go through a carefully structured and broad based programme, that will enable the students become fluent in Drawing/Draughting (Drafting) and modeling techniques and be capable of responding imaginatively to demands on their innovative ingenuity, creative - inventor spirit, Aesthetic and emotional sensibilities. (Wang, 2011). Along that same line of emphasis, AprotosoaieIftimi (2016) in her study of visual art/design curriculum and the new visual art / design language opined that "the visual arts/design curriculum should allow a wide range of activities aimed at developing the child/learner's imagination and creativity". Furthermore this she says "would be aimed at providing the learner with that balanced Educational Framework for the harmonious development of future professionals who can later in life bring such skills acquired to bear in helping to resolve the many problems faced by man in his designs (material culture) and built environment". Therefore, a well structured Design course must pay specific attention to the following three vital ingredients and elements of the course curriculum/content, and they are as follow:

(a) The arousal of curiousity in the natural and man-made worlds through the processes of observation and analysis, which gives an awareness of form and other Aesthetic values and a knowledge of prior art. The application of the principles of Biomorphism(Bio-Morphology) meaning the Biological state or study of the structure (Morphology) of plants and animals or living things.

(b) The ability that will help provide the opportunity for speculative thought and the creative exercise of ingenuity and skills of originality

(c) The development of creative skills, ability/ mental faculty to bring ideas and concepts (or products) to physical fruition.

Without the third element (c) above, (which is the development of creative skills ability/ mental faculty to bring Design ideas and concepts (or products) to physical function) no worth-while product can result. Clearly though, the conceptual stages preceed the "making" and no amount of emphasis on Design skills can compensate for a lack of design preparation. Although the processes of investigation, speculation and fabrication have been referred to separately, they are all important and are present at each stage in the design process (Langdon, 1978). It is pertinent here to emphasis this approach and the way in which the course functions, by highlighting one aspect of the course/programme. According to Lindkal (1984) who stated that "the aspect of Design that is to be paid specific attention to is that of proportion, structure and the interplay of parts". A quick examination of anything or an object will reveal that, it can be thought of as being made up of a number of parts. In the design of any product, (be it a logotype, a chair, car, bicycle or an airplane,) it is the proportioning of the parts in themselves and their relationship one to another that is the prime consideration. Shape, form, weight, mass, function and balance must all be considered if an elegant and coherent whole is to be achieved. Structure is very 
closely related to proportion, in fact the two quickly becomes inseparable as the problem of how parts are to fit, interlock, turn and move together is considered. (Brooks, 2010).

The greatest activity of conceiving, planning and making things has always been one of the most vital forces in the life of man and the Man-made environment. This broad areas of human endeavour is called "Design" and has resulted in artifacts and products as diverse as the "Mona Lisa", to the "PIN" and unto a "LASER or computer "CHIP". Modeling they say is the language of Design. How an object should look like, its proportions and how its parts should fit together and the mechanism by which it might operate are all communicated through drawings, models, plan, mock-ups and prototypes. So in order to engage in modeling and making things, one must first be actively engaged in Design activity. (Milton, 1995).

In any given design situation for instance, a picture would be regarded essentially, as a two-dimensional organization of shapes (which may be representing three - dimensional forms) and it is primarily the proportions of each shape in itself and the relationships between the shapes, that produces a sense of structure and the necessary sense of overall harmony and coherence. Equally, a good bicycle for example, must be well proportioned in all its parts, but here their mechanical and structural function would have to be influenced by their size and shape and ultimately the overall proportions of the machine. That is why Hopper (1977) opined that, these aspects of proportion and structure are key and central to all designing processes, and thus they figure prominently throughout any well co-ordinated Design Education course curriculum/programme.

In that same conext to Harahan (1978) suggests that the usual approach to this is by working out a discussion/brain-storming session with the students, about what the eyes sees in natural forms and man-made objects. Through a process of questions and answers one could come to realize that man makes objects, because of need; he sees a problem and solves it by designing and making or creating/inventing something to act as the problem-solving solution.(Milton, 1995). This is problem solving skills being put to the test.

\section{Design Conceptualization of the Product Brand: Importance and Implications in Design Education}

The life of a product brand begins with the birthing of a new idea/concept. The design concept is usually borne out of (or in) the mind of the designer, simulated either from or by experience, reasoning and / or imagination. The design concept could also be a generic or a basic form of abstraction or mental impression of a particular set of ideas or ideology of instances or occurrences in real life. It could also just be a contrived/ imaginative world. Conceptualization in Design could also be called a notion or an abstract or general idea inferred or derived from specific or simulated case scenarios (Obasuyi, 2010). Deducing or stretching that further, the issue of conceptualization of a new product according to David et.al (1982) could mean the invention or contrivance of an idea and 
sometimes the formulation this idea mentally and also sometimes this involves the formulation of such an idea mentally and ensuring it becomes a reality physically in the form of an actualized physical product, goods or service. According to Morris (2009) who stated that the conceptual development of a design and its product derivatives follows certain specific procedural, sometimes Algorithmic or other times Heuristic processes of the problem solving endeavour, which makes a design what its all about. One of the most fundamental of these processes / principles in the Activity called design and its education is referred to as - Sketching.

\section{Design Sketching}

Roozenburg et.al. (1995) explains that the term sketching could be said to represent those sketches, drawings and scribbling processes carried out at the rudimentary and fundamental stage in the design process. He expounded this further by saying that sketching could also be called drawing, draughting (draught-manship) or simply visualization processes (visuals). Some of these terms can be used interchangeably at the prescriptive stages of the design/product life span. Roozenburg et.al. (1995) also further puts it succinctly and states that; A sketch more often than not could imply (or refer to) "a loosely drawn art work or 2D drawing, were the sketch is used to a greater or lesser degree as a means for registering the intended work-able solution of the idea or concept derived from the original concept base".

Furthermore, sketching could be referred to as an art or applied graphic design project that is executed with such design equipments / tools like graphite, pencils, pen and ink, coloured markers, pastel, gouache poster colours or done directly on design compliant/enabled computers eg. use of computer software applications such as Element 3D video copilot, Autodesk MAYA, ALIAS software, Adobe After Effect, MAXON Cinema 4D, etc. Most of the contemporary design sketching and technological applications has long overtaken the old and Traditional/Conventional drawing (sketching) techniques that are utilized in the actualization process of bringing to life a new product. At some point in the design process the $2 \mathrm{D}$ paper sketching stage might just be eliminated altogether and the students can proceed directly to actualize the $3 \mathrm{D}$ digital image/model.

\section{Factors of Modeling, Styling in the Design Process of the Product Brand}

The design narrative of any given product involves the incorporation of all categories of Design professionals. They may include craftworkers, designers, coupled with the conceptual intuitiveness of the Applied Artists, sculptors, architects, graphic designers, Nanotechnologists, engineers, and visual display / 3D computer professionals, Nanosystems Analysts. When all these professionals are put together, they all help to bring to being the new product so desired. (Drexler, 1992).

\section{Modeling of the Product Brand (Clay - Kaolin - or Inductrial Plasticine)}

Clay and its uses in the design process is representative of any soft and malleable substance or material like industrial plasticine, Styrofoam or polymer clay which could also be used in the actualization of the form, body or 
morphological structure (buildup or makeup) of the intended product. For industrial design purposes, there are four types of clay or malleable substances that could be used in designing, building and sculpting of products. As mentioned earlier they include industrial plasticine, polymer clay, Styrofoam and kaolin clay. In each of these, the material composition and their application in the production processes vary considerably from one material to the other. For example, when using kaolin clay, the intended model or intended product is first created in Natural Kaolin clay, or in other times could be made up of a wooden or Iron frame called the "Armature" or also sometime made from the material called Styrofoam. As in the case of kaolin clay, the material is spread and smoothened over the frame or "Armature" using sculpting tools to shape and size the product intended into existence (Obasuyi, 2010).

According to Squires et.al. (2002) who stated that the physical actualization and conversion of the 3D Digital visual images (into this physical armature structure which forms the main skeletal frame for the actualization of the prototype concept of product) becomes the cornerstone for the actual modeling/product of the prototype concept. The prototype concept so created and is realized from the wholesome initial clay body (or industrial plasticine or Styrofoam) using various modeling/styling techniques of scalping, scraping, moulding/modeling burnishing, deletion and retention of forms / shapes, which are sometimes either Accentuated, highlighted or played down as the need arises to make way, create or help to achieve the final curvilinear, structural, body, shape or form of the intend product desired. The eventual prototype copy so realized is further subjected to the process of final actualization with the use and application of the fibre glass material. This material is a polyvinyl chloride based, tough plastic material, which is viscous when prepared with petrochemical solvent/solution and poured unto the plaster of Paris (POP) mould which is called the "NEGATIVE", that has hitherto been taken or gotten from the original clay model/body. The fibre glass paste is poured unto the mould of P.O.P which then solidifies to form the final look-a-like of the Real product/brand. This is further primed, sandblasted, smoothened to the fine, smooth and perfect surface finish body, made ready for the paint job and final product design/ finish.

\section{Design Styling}

David et. al. (1982) explain that in styling all the design concepts and 2-D visuals so realized are translated or transformed into 3D digital imaging/surface modeling to ensure that the $3 \mathrm{D}$ models so developed meets with the Aesthetic requirements and specifications of the designers expectation. As well as meets with all the engineering, manufacturing specifications and requirements. Styling as a technique in the design process, ensures that both the technical as well as the Aesthetics components harmonises for the optimal utility, form and function of the intended design product. Tools mostly used in styling by product engineering styling teams are Autodesk, Alias and ICEM SURF software tools. The styling production team often consists of the chief industrial designers, interior designers and the engineering experts. In some case all three roles are 
roled into one designer. Other members of the production team are the colour and trim designer, the clay model team, the styling team, studio heads/managers, prototype engineers/designers. An average number of members of a design team for example could reach up to 20 and the time frame for a concept's developmental completion could range from between 24 to 36 months in certain instances.

\section{Conclusions}

The factors that create and generate Designs are often times embedded in the very innate core of the Designed object itself, this factor is only amplified through and by its process/es of production. (Aspelund, 2010) Such factors as those of ideation, conceptuation, sketching, modeling, styling, prototype (or prototype production) are vital in the final production or manufacture of the product brand in question. This often evokes the application of the skills and creative ingenuity of the Designer who helps bring all those factors to play (or to bear) starting from the birthing of new concepts/ideas unto the final actualization of the Design initiative/s or project.

The designer in this case needs to skillfully and carefully manage these elements (and all other various factors) of Design, such as colour/s, materials, Form, modeling, styling, prototype design, 3D Digital imaging, Brand creation and Branding characteristics, which helps to create that maximum impact in the products uniqueness over its other competing Brands. The role/function of Aesthetics in the Design and Branding process of the product is further enhanced and accentuated by the ability of the Designer to skillfully manipulate the products material and physical content to help achieve that unique Ephemeral quality.

The product Brand and its role on the order hand is intrinsically related to the value, service and function it is intended to perform. Where the meaning of the brand could be said to be that recognizable kind of product that represents a Name given to an object, product or service, which marks it or labels it, by using a distinctive word, sign or symbol that ultimately indicates its exclusive right of usage with legal rights or patent. The Brand (or product Brand) could also refer to a set of marketing and communication strategy/s or methods which helps to distinguish one individual or group/s of people or company from the others. This includes the Brands identity, like its Logo and Trademark. It could be a Name, a term, design symbols or other characteristic features that distinguishes the product or Brand from those of its competitors.

The roles and factors of Aesthetics, modeling, styling and product branding in Design simply put means the ability to harmonise those factors and bring them to bear on the quality, beauty and purchaseability of the product. As the product exudes those qualities of Beauty, Colours, shape, Form and the perfect portrayal of the general Aesthetic Ambience of Excellence, finesse, elegance and perfection. Then these roles and attributes of the Brands will definitely ensure its marketability, profitability and ultimate success. The implications of all of these in Design Education is the potential of the Design 
Educator / Teacher to effectively harmonise the various approaches and practices of a functional Design-led Educational programme that is able to prepare students and develop their abilities and innate potentials early for a well defined future of Design excellence in practice. This could be achieved by tailoring/piloting these talents to practicable and useful ends as professionals in Design and Technology (Alberty \& Alberty 1962).

\section{Bibliography}

1. Alberty, H.B. \& Alberty, E.J. (Eds.). (1962). Re-organising the High School curriculum. New York: Macmillian.

2. Aprostosoaie-Iftimi, A.M. (2016). The openness of the visual art curriculum towards a new visual art language. Review of Artistic Education, 11/12, 175182.

3. Aspelund, K. (2010). Design process. New York: Fawchild Book Pub.

4. Baynes, K. (1978). Project on Design in General Education - Department of Design, Royal College of Art. London: Addision-Wesley prof. Pub.

5. Brooks, F.P. (2010). The Designs of Designs. London: Addison-Wesley Prof. Pub.

6. David, F. W. \& Noller, N. (1982). Experimental modeling in Engineering. London: Butter Worths Pub.

7. Drexler, A. (1992). Nanosystems, molecular machinery, manufacturing and computation. New York: John Wiley and Son.

8. Frankenberger, E \& Badke-Schaub, P. (1998). Designers - The Key to successful product Development. London: Springer Pub.

9. Harahan, J. (1978). Design in General Education (Eight Projects) Jolly and Barber Limited. London: Rugby and Design Council Pub.

10. Hopper. L. (1977). The curriculum context, design and development Oliver and Boyd. Edinburgh: Open University Press.

11. Knapp, D. (2008). The Brand Promise. New York: MacGraw Hill Pub.

12. Korsmeyer, C. (Ed.). (1998). Aesthetics the Big question. Chicago: Basic Books.

13. Langdon, R. (1978). Project on Design in General Education. Department of Design research, Royal College of Art London publichsed by Design Council. 14. Lindkal, C.M. (1984). Defining Education Objective. Pittsburgh Pennsytvama: University of Pittsburgh Press.

15. Loewy, R. (1980). Industrial Design. London: Fourth estate Ltd. Pub.

16. Lucie-Smith, E. (Ed.). (2001). History of Industrial Design. Oxford: Oxford Phaidon Press.

17. Martins, J. S. (2000). The Emotional Nature of a Brand. Rio-Brazil: Marts Plan Imagen Ltd press.

18. Milton, K. (1995). Design Principles and practice - creativity and conceptual Design. London: Open university press/pub.

19. Morris, R. (2009). The Fundamentals of Product Design. London: AVA Pub. 
20. Obasuyi, O.F.E. (2010). Industrial Design the Nexus between Arts \& Technology. Nigeria, Art Reflections. Journal of Society of Nigerian Artist, 9. 21. Ollins, W. (2003). On Brand. London: Thames and Hudson.

22. Papanek, V. (2009). Design for the Real World. In Human Ecology and Social Change ( $2^{\text {nd }}$ ed.) London: Thames and Hudson Pub.

23. Roozenburg, J. M \& Eekels, J. (1995). Product Design fundamentals and methods of Design. New York: John Wiley and Sons.

24. Rusu, M. \& Chandrinou, T. (2015). Characteristics and Principles of Art Education. Review of Artistic Education, 10/11.

25. Schmidt, K. \& Ludlow, C. (2002). Inclusive Branding. Basingstoke: Palmgrave Macmillan Pub.

26. Shimura, A. P. \& Palmer, S. E. (2012). Aesthetic Science. Oxford: Oxford University Press.

27. Squires, S. \& Byrne, B. (2002). Creating Breakthrough Ideas. The Collaboration of Anthropologists and Designer in the Product Development Industry. Westport, CT. USA: Bergin and Garvey Pub.

28. Wang, T. J. (2011). Designing for Designing. ICT Technologies and professional Education. International Journal of Art and Design Education, 30. Wilson, J. (2002). The design of objects and the objects of design. In Design and the Social Sciences. New York: Taylor and Francis 